\title{
Synergistic suppression of human breast cancer cells by combination of plumbagin and zoledronic acid in vitro
}

\author{
Han QIAO ${ }^{1, \#}$, Ting-yu WANG ${ }^{2, \#}$, Wei YAN ${ }^{1,3}$, An QIN $^{1}$, Qi-ming FAN ${ }^{1}$, Xiu-guo HAN ${ }^{1}$, Yu-gang WANG ${ }^{1}$, Ting-ting TANG ${ }^{1, *}$ \\ Shanghai Key Laboratory of Orthopaedic Implants, ${ }^{1}$ Department of Orthopaedic Surgery, ${ }^{2}$ Department of Pharmacy, Shanghai Ninth \\ People's Hospital, Shanghai Jiao Tong University School of Medicine, Shanghai 200011, China; ${ }^{3}$ Wendeng Zhenggu Hospital of \\ Shandong Province, Wendeng 264400, China
}

\begin{abstract}
Aim: Zoledronic acid (ZA), a bisphosphonate, is currently used in combination with chemotherapeutic agents to suppress breast cancer cell proliferation or breast cancer-induced osteolysis. The aim of this study was to investigate the effects of ZA combined with a natural anticancer compound plumbagin (PL) against human breast cancer cells in vitro.

Methods: Human breast cancer MDA-MB-231SArfp cells were treated with ZA, PL or a combination of ZA and PL. The cell growth, apoptosis and migration were evaluated using CCK-8 assay, flow cytometry and transwell assay, respectively. The expression of apoptosis-related proteins was measured using real-time PCR and Western blotting. Synergism was evaluated using Compusyn software, and the combination index $(\mathrm{Cl})$ and drug reduction index (DRI) values were determined.

Results: PL or ZA alone caused mild cytotoxicity (the $\mathrm{IC}_{50}$ value at $24 \mathrm{~h}$ was 12.18 and above $100 \mu \mathrm{mol} / \mathrm{L}$, respectively). However, the combination of ZA and PL caused a synergistic cytotoxicity $(\mathrm{Cl}=0.26)$. The DRI values also showed a synergistic effect between PL and ZA, with actual values of 5.52 and 3.59, respectively. Furthermore, PL and ZA synergistically induced apoptosis and inhibited migration of the breast cancer cells. Moreover, the combination of ZA and PL decreased the expression of Notch-1, cleaved PARP, Bcl-2 and Bcl-xl, and increased the expression of cleaved caspase-3, CDKN1A and ID1. When the breast cancer cells were transfected with specific siRNA against Notch-1, the combination of ZA and PL markedly increased the expression of Bcl-2.

Conclusion: Combination of ZA and PL synergistically suppresses human breast cancer MDA-MB-231SArfp cells in vitro. PL can inhibit ZA-induced activation of the Notch-1 signaling pathway and subsequently reduce the expression of Bcl-2, thus potentiating cancer cell apoptosis.
\end{abstract}

Keywords: plumbagin; zoledronic acid; anticancer agent; human breast cancer; synergism; apoptosis; Notch-1; Bcl-2

Acta Pharmacologica Sinica (2015) 36: 1085-1098; doi: 10.1038/aps.2015.42; published online 3 Aug 2015

\section{Introduction}

The most common metastatic site of advanced breast cancer is bone, which is observed in two-thirds of patients with malignant metastatic breast tumors ${ }^{[1]}$. Individuals with such metastatic complications may be affected by subsequent skeletalrelated events (SREs), which were first identified as intractable bone pain, pathological fractures, spinal cord compression (SCC) and hyperkalemia, thus significantly increasing the morbidity and mortality of this malignancy ${ }^{[2]}$.

Bone modifying agents such as bisphosphonates (BPs) and denosumab have been shown to be efficacious in protecting

\footnotetext{
\#These authors contributed equally to this work.

* To whom correspondence should be addressed.

E-mail ttt@sjtu.edu.cn

Received 2015-02-07 Accepted 2015-04-15
}

against metastatic progression. BPs such as zoledronic acid (ZA), which is the most potent inhibitor of bone resorption, is currently used as an adjuvant treatment in women with early metastatic cancer. Numerous studies have demonstrated that ZA is capable of inhibiting breast cancer bone metastasis by impeding osteoclast recruitment, proliferation, and differentiation from preosteoclast cells ${ }^{[3,4]}$, particularly by decreasing the osteolytic activity of mature osteoclasts ${ }^{[5-7]}$. With respect to tumor cells, research into the cytotoxic influence of BPs on breast cancer cell viability has diverged dramatically ${ }^{[8-11]}$, with reported cytotoxic 24 -h half-maximal inhibitory concentration $\left(\mathrm{IC}_{50}\right)$ values ranging from 10 to $100 \mu \mathrm{mol} / \mathrm{L}$, even in the same cell line. In some cases, ZA does not exhibit explicit proliferative inhibition in the MDA-MB-231 breast cancer cell line. Nevertheless, evidence of the effects of ZA on the regulation of tumor cell apoptosis has been universally recognized ${ }^{[12-14]}$. 
Therefore, researchers have sought new strategies that combine ZA with other chemotherapeutic agents or nutraceuticals, including paclitaxel, doxorubicin, cisplatin, camellia sinensis and gemcitabine, to treat osteosarcoma, breast cancer and multiple myeloma ${ }^{[15-17]}$. Synergistic effects have been shown to affect various types of tumor cells, regardless of the uncertain cytotoxicity of individual drug treatments ${ }^{[18-20]}$.

Plumbagin (5-hydroxy-2-methyl-1,4-naphthoquinone) (PL) is derived from the traditional Chinese medicinal plant Plumbago Zeylanica; it is an analog of vitamin $\mathrm{K} 3$ and is currently under extensive investigation. Historically, PL has been used in traditional Chinese and Indian medicine to treat microbial infections ${ }^{[2]]}$, atherosclerotic diseases ${ }^{[22]}$, inflammatory problems ${ }^{[23]}$ and cancer-associated issues both in vivo ${ }^{[2,25]}$ and in vitro $^{[26,27]}$. Our previous studies have indicated that PL can effectively attenuate the proliferation of breast cancer cells and concomitant osteoclast formation in the bone microenvironment ${ }^{[28]}$. Moreover, the PL-mediated inhibition of migration and invasion in breast cancer cells has been confirmed through the suppression of the signal transducer and activator of transcription 3 (STAT3) signaling pathway and the production of inflammatory cytokines ${ }^{[29]}$. Other researchers have suggested that PL impedes tumor cell proliferation, induces apoptosis and decreases cell metastasis ${ }^{[30]}$. However, despite these clear and striking effects in tumor cells, whether PL can exhibit synergistic effects when combined with other commonly used drugs remains unknown.

Therefore, we combined PL with ZA to enhance their mutual inhibition of cell viability and increase overall apoptosis. In this study, ZA was used as a pharmacological strategy to explore whether PL can be used as a synergistic drug to enhance combinative efficacy in a human breast cancer cell line and provide advantageous therapeutic effects. Moreover, the underlying mechanisms of apoptosis via combined treatment were also investigated to gain a better understanding of the combinatorial effects of PL and ZA.

The Notch signaling pathway plays a significant role in proliferation, differentiation and apoptosis. Four Notch receptors (Notch 1-4) have been identified ${ }^{[31]}$, and several recent studies have reported numerous novel Notch target genes, including Cluster of Differentiation 28 (CD28), GIMAP5, ID1, nuclear factor-kappaB (NF-kB), cyclin-D1 and cyclin-dependent kinase inhibitor 1A $(\mathrm{CDKN} 1 \mathrm{~A})^{[31-33]}$. The role of Notch receptors in cancer cells has been confirmed by the observed increase in Notch-1 levels in poorly differentiated human mammary carcinomas $^{[34]}$. Additional studies have further demonstrated that inhibition of the Notch-1 signaling pathway is responsible for increased apoptosis as well as decreased proliferation and invasiveness in tumor cells through interactions with other signaling pathways, including the protein kinase B (Akt), mammalian target of rapamycin (mTOR), NF-kB, matrix metalloproteinase-9 (MMP-9) and urokinase-type plasminogen activator (uPA) pathways ${ }^{[35,36]}$. As a result, we intend to determine whether similar effects on Notch-1 expression can be achieved by individual or combined administration of PL and ZA. Furthermore, feasible downstream targets of the
Notch family with respect to apoptosis bioactivity were investigated to explore the potential signaling pathway that may be mediating the effects of PL and ZA in combination.

\section{Materials and methods \\ Main reagents}

PL, ZA, and dimethyl sulfoxide (DMSO) were purchased from Sigma-Aldrich (St Louis, MO, USA). PL was dissolved in DMSO and ZA was dissolved in $0.9 \%$ physiological saline at concentrations of 100 and $10 \mathrm{mmol} / \mathrm{L}$, respectively. The synergistic group contains equal volumes PL and ZA. These reagents were stored in the dark at $-20^{\circ} \mathrm{C}$. Stock solutions were diluted further into cell culture medium immediately before use. Primary antibodies against Notch-1, Notch-2, Notch-3, caspase-3, cleaved (clv) caspase-3, B-cell lymphoma 2 (Bcl-2), Bcl-xL, and glyceraldehyde 3-phosphate dehydrogenase (GAPDH) were purchased from Cell Signaling Technology (Danvers, MA, USA), and antibodies against clv poly (ADP-ribose) polymerase (PARP), CDKN1A and ID1 were obtained from Abcam (Cambridge, UK).

\section{Cell line and cell culture}

The estrogen-independent human breast cancer cell subline MDA-MB-231SArfp was kindly provided by Prof Jiake XU (University of Western Australia, Australia). These cells were previously generated by T YONEDA (University of Texas Health Science Center, San Antonio, TX, USA) from an intracardiac injection of MDA-MB-231 cells followed by in vivo selection for cells that exhibited the inclination to metastasize to and grow in a bone microenvironment ${ }^{[37]}$. The MDA-MB231SArfp cells were generated by the stable transfection of the pDsRed2-N1 construct ${ }^{[38]}$ (Clontech, Mountain View, CA, USA). This cell line was cultured in Dulbecco's modified Eagle's medium (DMEM, Gibco, Invitrogen Ltd, Carlsbad, CA, USA) supplemented with $10 \%$ fetal bovine serum (FBS), $1 \%$ penicillin-streptomycin solution and $0.75 \mathrm{mg} / \mathrm{mL} \mathrm{G}-418$ (Gibco, Invitrogen Ltd, Carlsbad, CA, USA) at $37^{\circ} \mathrm{C}$ in a humidified atmosphere with $5 \% \mathrm{CO}_{2}$.

\section{Cell viability assay}

Cell viability was measured using the Cell Counting Kit-8 (CCK-8) according to previously reported methods ${ }^{[39]}$. Briefly, MDA-MB-231SArfp cells were suspended and plated in a 96-well plate (6000 cells/well) overnight without drugs. Then, the cells of the control group were treated with vehicle (DMSO), whereas the PL and ZA groups were treated with various concentrations of PL $(0-20 \mu \mathrm{mol} / \mathrm{L})$ and ZA $(0-100 \mu \mathrm{mol} / \mathrm{L})$, respectively. The synergistic groups were treated with equal ratios of PL and ZA at different concentration combinations. From one to four days after drug stimulation, the optical density (OD) of the wells at $490 \mathrm{~nm}$ was measured using a microplate reader (Thermo Electron Corp, Waltham, MA, USA) after incubation with CCK8 solution at $37^{\circ} \mathrm{C}$ for $2 \mathrm{~h}$. Each condition included eight replicate wells with at least three independent repeats. 


\section{Analysis of synergistic effects}

Synergism was analyzed by the software Compusyn as previously described ${ }^{[40]}$, with the process derived from the median effect principle of Chou and Talalay ${ }^{[41]}$. Data from the cell viability inhibitory experiments described above were employed to perform this statistical analysis. The combination-index (CI) is a numerical index that is calculated by using following formula ${ }^{[42]}$ : $C I=D_{1} /\left(D_{x}\right)_{1}+D_{2} /\left(D_{x}\right)_{2}$, where $D_{1}$ and $D_{2}$ are the concentrations of reagent 1 and 2 applied in combination to achieve $x \%$ of total drug effect, whereas $\left(D_{x}\right)_{1}$ and $\left(D_{x}\right)_{2}$ represent the concentrations of individual agents to accomplish the same efficacy. The CI value is a mathematical and quantitative representation of the pharmacological interplay of two drugs ( $\mathrm{CI}>1$, antagonism; $\mathrm{CI}=1$, additive; $\mathrm{CI}<1$, synergism). Based on the data obtained from the growth inhibition experiment and computerized software, CI values were generated from a range of fraction affected (Fa) levels from 0.05-0.9 (5\%-90\% growth suppression). The Fa-CI plot and Fa-log (CI) plot illustrate the actual CI values at diverse suppressive levels. The dose-reduction index (DRI) represents the actual fold-change of dose attenuation in a synergistic combination at a given effect level compared with the drug alone. A DRI value of more than 1 is of practical significance because it signifies therapeutic importance under circumstances in which the dose of any specific component of combinatorial drugs is reduced to ameliorate side effects caused by cytotoxicity to normal cells. The Fa-DRI plot and Fa-log (DRI) plot indicate the DRI values of each drug at different levels based on computer simulations.

\section{Annexin V/propidium iodide immunofluorescence}

Cell apoptosis was measured by flow cytometry using annexin $\mathrm{V} /$ propidium iodide (PI) double-immunofluorescent staining. MDA-MB-231SArfp cells treated for $24 \mathrm{~h}$ with increasing concentrations of PL or ZA, either alone or in combination, were harvested, vigorously pipetted, and subsequently collected to verify drug-induced apoptosis rates using the Annexin V-FITC/PI Kit (Bender Medsystems, Burlingame, CA, USA) according to the manufacturer's protocols. Apoptotic events were indicated as a combination of fluorescein isothiocyanate $\left(\right.$ FITC) ${ }^{+} / \mathrm{PI}^{-}$(early apoptotic) and $\mathrm{FITC}^{+} / \mathrm{PI}^{+}$(late apoptotic or dead) events. The final results are expressed as the percentage of FITC $^{+}$cells after subtracting the number of vehicle cells.

\section{Tumor cell migration ability}

The cell migration potential was detected using a Transwell assay with $8-\mu \mathrm{m}$ cell culture inserts (Millipore Corporation, Billerica, MA, USA) in 24-well plates. Drug-treated MDA-MB231SArfp cells $\left(3 \times 10^{4}\right.$ cells/well $)$ were suspended in $100 \mu \mathrm{L}$ of serum-free DMEM and added to the upper chamber of the transwells, whereas the lower chamber was filled with $550 \mu \mathrm{L}$ complete DMEM with $20 \%$ FBS. In cell migration assays, the cells were incubated at $37^{\circ} \mathrm{C}$ for $24 \mathrm{~h}$. Subsequently, the transwell membrane was fixed in $4 \%$ paraformaldehyde for 30 min and stained with $0.1 \%$ crystal violet for $15 \mathrm{~min}$, and the cells were then scraped from the top of chamber with a cotton swab. For quantification, the number of migrating cells was counted under a microscope in five random fields at $\times 100$ magnification and reported as the mean \pm SD (standard deviation). All assays were repeated three times independently.

\section{Quantitative real-time PCR}

Twenty-four hours after treatment with different doses of PL and ZA, either alone or in combination, RNA was extracted from MDA-MB-231SArfp cells using the TRIzol method, and the concentration and purity were measured. A reverse transcription kit (iScript cDNA Synthesis Kit, Bio-Rad, Hercules, CA, USA) was used to synthesize cDNA using the reverse transcriptional method. mRNA expression levels were evaluated by real-time PCR (Reagent Kit: SYBR ${ }^{\circledR}$ Premix Ex Taq ${ }^{\mathrm{TM}}$, TliRNase H Plus, Takara, Tokyo, Japan) according to the manufacturer's instructions. The relevant primers are listed in Table 1.

\section{Western blotting}

Protein extracts from MDA-MB-231SArfp cells subjected to various treatments were prepared using radio-immunoprecipitation assay (RIPA) lysis buffer supplemented with $1 \mathrm{mmol} / \mathrm{L}$ phenylmethylsulfonyl fluoride (PMSF) and were quantified using a BCA Protein Assay Kit (Thermo Scientific, IL, USA). Lysates were diluted 5:1 with loading buffer and heated to denature at $99^{\circ} \mathrm{C}$ for $10 \mathrm{~min}$. Equal amounts of protein (30 $\mu \mathrm{g}$ ) were resolved by sodium dodecyl sulfate polyacrylamide gel electrophoresis (SDS-PAGE) on a precast gel (7.5\%-12.5\%) at $80 \mathrm{~V}$ for $30 \mathrm{~min}$ and $120 \mathrm{~V}$ for $1 \mathrm{~h}$. The proteins were then transferred to an activated polyvinylidene fluoride (PVDF) membrane by wet electrophoretic transfer (Bio-Rad Laboratories, Hercules, CA, USA) for $2.5 \mathrm{~h}$ at a constant current of $250 \mathrm{~mA}$. The membranes were blocked for $1 \mathrm{~h}$ in Tris-buffered saline (TBS) containing 0.05\% Tween 20 (TBST) and 5\% nonfat milk powder and then incubated overnight with primary antibody at $4^{\circ} \mathrm{C}$. After three washes in TBST, the membranes

Table 1. Primer sequences for real-time PCR analysis.

\begin{tabular}{llll}
\hline Gene & \multicolumn{1}{c}{ Forward primer } & Reverse primer & $\begin{array}{c}\text { Product } \\
\text { length/bp }\end{array}$ \\
& & & \\
Notch-1 & GACAGCCTCAACGGGTACAA & ATACACGTGCCCTGGTTCAG & 227 \\
Notch-2 & ATACAGATGCGAGTGTGTCCC & ATCCCCTGAACACTAAGATGGA & 223 \\
Notch-3 & CTTCCTGCGATCAGGACATCA & CCATTGAAGAGGAGCTGGG & 277 \\
GAPDH & CCTGCACCACCAACTGCTTA & AGGCCATGCCAGTGAGCTT & 178 \\
\hline
\end{tabular}


were probed with the corresponding secondary antibody for $1 \mathrm{~h}$ at room temperature. The membranes were washed again in TBST, and the protein bands were visualized using an Odyssey Infrared Imaging System (LI-COR, Biosciences, Lincoln, NE, USA).

\section{DAPT administration and siRNA transfection against Notch-1}

DAPT $\{N$-[N-(3,5-difluorophenacetyl)-L-alanyl]-S-phenylglycine $t$-butyl ester\}, an inhibitor of the $\gamma$-secretase complex of the Notch signaling pathway, was utilized to inhibit Notch-1 signaling in MDA-MB-231SArfp breast cancer cells. The cells were incubated with DAPT $(20 \mu \mathrm{mol} / \mathrm{L})$ in a six-well plate for $24 \mathrm{~h}$. Subsequently, DAPT was removed, and the cells were washed twice with fresh medium before drugs were added. Western blotting was employed to evaluate the similarity between the synergism group and the ZA with DAPT group with respect to the expression of $\mathrm{Bcl}-2$.

To further explore the potential relationship between Notch-1 and Bcl-2, siRNA duplexes against human Notch-1 were prepared by Shanghai GenePharma Co, Inc (Shanghai, China). The siRNA sequences of Notch-1 are shown below in Table 2. Twenty-four hours after cells were seeded in sixwell plates at $70 \%-80 \%$ confluency, the MDA-MB-231SArfp cells were transfected with siRNA at a final concentration of $0.1 \mu \mathrm{mol} / \mathrm{L}$ using Lipofectamine 2000 transfection reagent (Invitrogen, Carlsbad, CA, USA). RT-PCR and Western blotting for Notch-1 expression were used to evaluate the efficacy of siRNA silencing. Twenty-four hours after transfection, 7.5 $\mu \mathrm{mol} / \mathrm{L}$ PL with or without $50 \mu \mathrm{mol} / \mathrm{L}$ ZA was added to the plate to evaluate the role of Notch-1 in Bcl-2 regulation. Western blotting was performed to investigate Bcl-2 expression in the treatment groups.

\section{Statistical analysis}

An analysis of variance (ANOVA) was used to evaluate the statistical significance of the data obtained among the groups. A $P$-value of less than 0.05 was considered statistically significant. All of the data were analyzed with SPSS 13.0 software (Statistical Package for the Social Sciences, Chicago, IL, USA) and are presented as the mean \pm SD.

\section{Results}

In vitro cytotoxic synergism of plumbagin and zoledronic acid on MDA-MB-231SArfp cells

To explore the possibility of synergistic cytotoxicity, MDA-
MB-231SArfp cells were treated with various concentrations of PL and ZA, either alone or in combination. As shown in Figure 1, PL and ZA at up to 20 and $100 \mu \mathrm{mol} / \mathrm{L}$, respectively, each exhibited dose-dependent cytotoxicity in MDA-MB231SArfp cells from 24 to $96 \mathrm{~h}$. In the PL-treatment group, the 24-h $\mathrm{IC}_{50}$ was $12.18 \mu \mathrm{mol} / \mathrm{L}$, whereas in the ZA-treatment group, the $24-\mathrm{h} \mathrm{C}_{50}$ was exceeded $100 \mu \mathrm{mol} / \mathrm{L}$, and the 48 - $\mathrm{h}$ $\mathrm{IC}_{50}$ was $67.36 \mu \mathrm{mol} / \mathrm{L}$. Only high concentrations (10 and 5 $\mu \mathrm{mol} / \mathrm{L}$ ) inhibited cell viability in the PL group, which was similar to that observed in the ZA group, in which cytotoxicity was demonstrated only for the $100-\mu \mathrm{mol} / \mathrm{L}$ treatment. Following consecutive drug interventions, the cytotoxic effect increased as the effective administration dose dropped to the minimum value of $0.625 \mu \mathrm{mol} / \mathrm{L}$ in the PL group and 3.125 $\mu \mathrm{mol} / \mathrm{L}$ in the ZA group at $96 \mathrm{~h}$. When administered simultaneously, the treatment efficacy increased relative to either reagent alone. As shown in Figures 2A and 2B, during the first 24-h treatment, only $10 \mu \mathrm{mol} / \mathrm{L}$ PL exhibited a synergistic effect to every ZA concentration, which was similar to that of $100 \mu \mathrm{mol} / \mathrm{L}$ ZA in each PL group. Furthermore, a synergistic effect could be observed in the 5- $\mu \mathrm{mol} / \mathrm{L}$ PL group with all concentrations of ZA. No synergism was evident in the 10- $\mathrm{\mu mol} / \mathrm{L}$ PL group, irrespective of the actual concentration of ZA. From 48 to $96 \mathrm{~h}$, both 5 and $10 \mu \mathrm{mol} / \mathrm{L}$ PL were capable of significantly reinforcing the cytotoxicity of $\mathrm{ZA}$, although $2.5 \mu \mathrm{mol} / \mathrm{L}$ PL only showed an effect after $96 \mathrm{~h}$ of treatment. Furthermore, none of the PL concentrations were shown to be instrumental in enhancing the cytotoxicity of 50 and 100 $\mu \mathrm{mol} / \mathrm{LZA}$ treatments at $96 \mathrm{~h}$. For the PL treatment group combined with various concentrations of $\mathrm{ZA}$, synergistic efficacy was observed for almost all doses of ZA, despite the relative absence of synergism of $10 \mu \mathrm{mol} / \mathrm{L}$ PL with ZA.

The above results suggest that combination treatments of MDA-MB-231SArfp cells are synergistic, and this effect can also be observed with the $\mathrm{CI}$ and DRI values (Figure 2C). The $\mathrm{CI}$ values represent the quantitative interaction between the drugs and were calculated using Compusyn software at different Fa levels. Figure 2Ca and $2 \mathrm{Cb}$ demonstrate that in MDAMB-231SArfp cells, the combination of PL and ZA produced an explicit synergistic effect and had a CI value of less than 1 at most Fa levels. The synergism was particularly obvious at lower inhibitory concentrations, whereas little impact was observed at higher proliferation suppression. The CI values were 0.26 and 0.46 when the Fa values were 0.5 and 0.7 , respectively, but the value was 1.55 when Fa was 0.8. These

Table 2. siRNA duplexes and Notch-1 sequences.

\begin{tabular}{lll}
\hline \multicolumn{1}{c}{ RNA oligo } & Forward sequence & Reverse sequence \\
\hline Negative control & UUCUCCGAACGUGUCACGUTT & ACGUGACACGUUCGGAGAATT \\
Notch1-siRNA-3916 & CGUCAUCAAUGGCUGCAAATT & UUUGCAGCCAUUGAUGACGTT \\
Notch1-siRNA-780 & GUCCAGGAACAACUGCAATT & UUGCAGUUGUUUCCUGGACTT \\
Notch1-siRNA-2010 & CAGGGAGCAUGUGUAACAUTT & AUGUUACACAUGCUCCCUGTT \\
Notch-1-Homo & GACAGCCTCAACGGGTACAA & ATACACGTGCCCTGGTTCAG \\
GAPDH & AGGCCATGCCAGTGAGCTT & AGGCCATGCCAGTGAGCTT \\
\hline
\end{tabular}


A
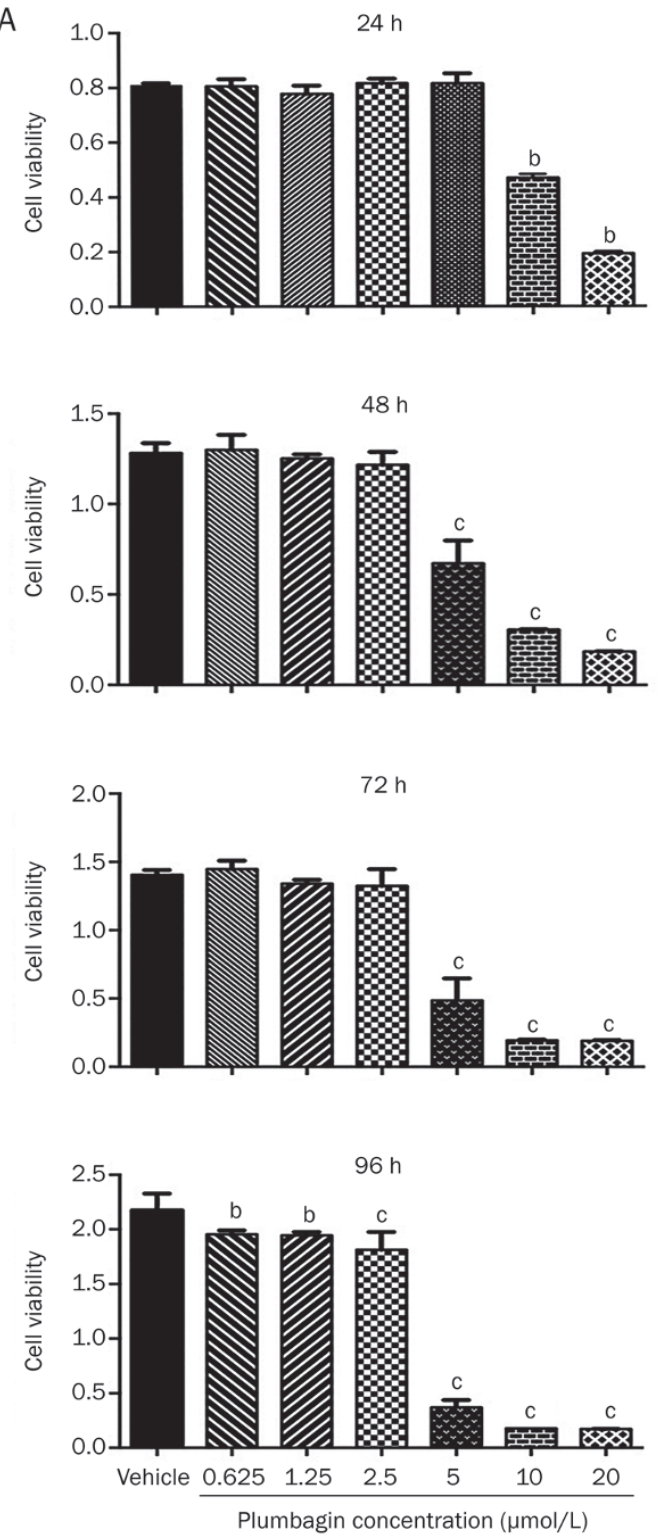

B
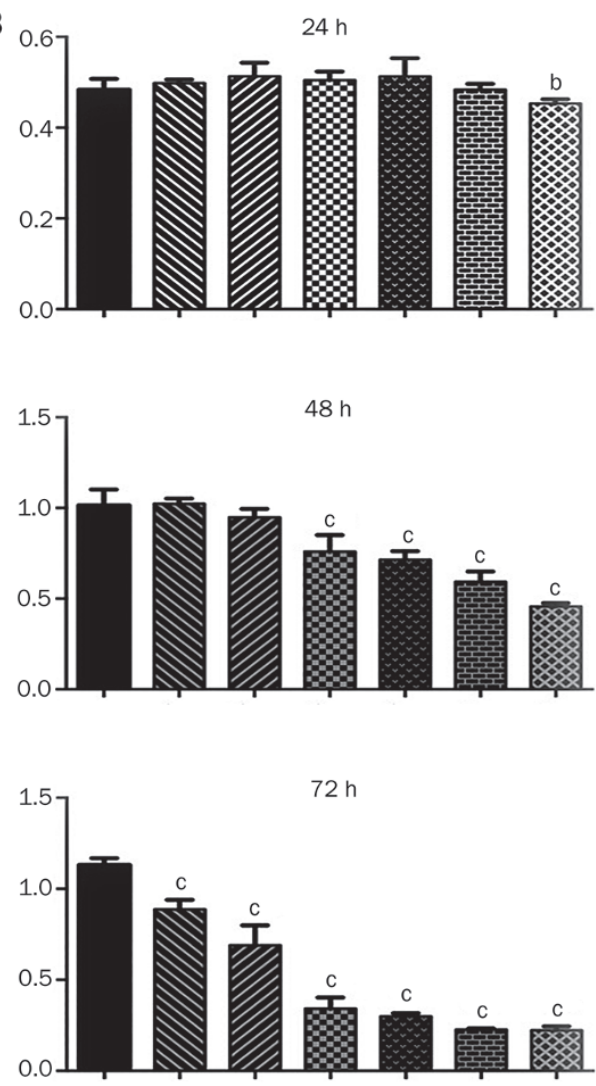

$96 \mathrm{~h}$

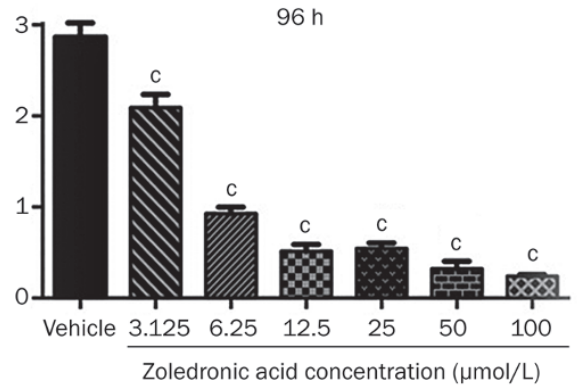

Figure 1. In vitro cytotoxicity of plumbagin or zoledronic acid in MDA-MB-231SArfp breast cancer cells. The inhibition of MDA-MB-231SArfp cell growth after treatment with $\mathrm{PL}(\mathrm{A})$ or $\mathrm{ZA}(\mathrm{B})$ for $24,48,72$, and $96 \mathrm{~h}$. All data represent the means $\pm \mathrm{SD}$ of at least three independent experiments. ${ }^{\mathrm{b}} \mathrm{P}<0.05$, ${ }^{\mathrm{c}} P<0.01$.

values confirmed a significant synergistic in vitro antitumor effect in the majority of PL and ZA combination treatments, whereas synergism can barely be detected at most of the cytotoxic drug concentrations. The Fa-DRI plot demonstrates whether the influence of synergistic treatments can be of therapeutic value in practical clinical strategies. Figure 2Cc and $2 \mathrm{Cd}$ indicate that most of the two-reagent doses may have benefit clinical practices, with DRI values well above $1(\mathrm{Fa}=0.5$, $\mathrm{DRI}_{\mathrm{PL}}=17.06, \mathrm{DRI}_{\mathrm{ZA}}=4.86 ; \mathrm{Fa}=0.7, \mathrm{DRI}_{\mathrm{PL}}=5.52, \mathrm{DRI}_{\mathrm{ZA}}=3.59$ ). Similarly, no therapeutic effects can be predicted for Fa values greater than 0.9 in the PL group, where ZA is of clinical benefit. These findings are consistent with the growth-inhibition efficiency of PL and ZA and further confirmed our hypothesis that synergism occurs when PL and ZA are given in combination. Therefore, it is necessary to further examine the effects of drug combinations on a wider range of phenotypes to identify the underlying mechanism of action.

Flow cytometric analysis of enhanced cell apoptosis by plumbagin or zoledronic acid alone and in combination

The translocation of phosphatidylserine from the inner leaflet to the outer leaflet of the plasma membrane during the early stages of apoptosis can be assessed using the phospholipidbinding protein annexin V. Flow cytometry revealed that PL and ZA, either individually or in combination, were able to generate a dose-dependent increase in the apoptotic and post- 
A

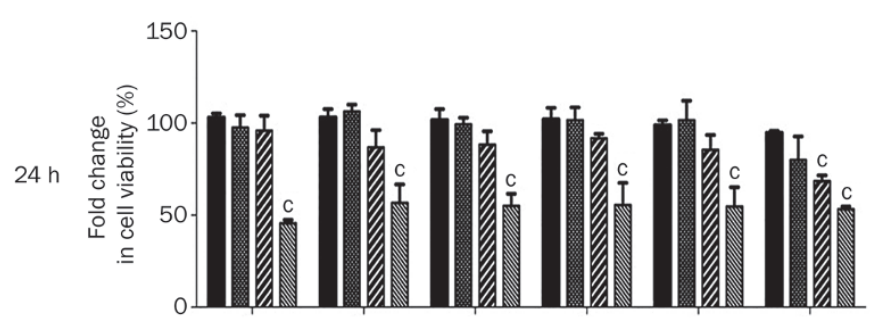

B
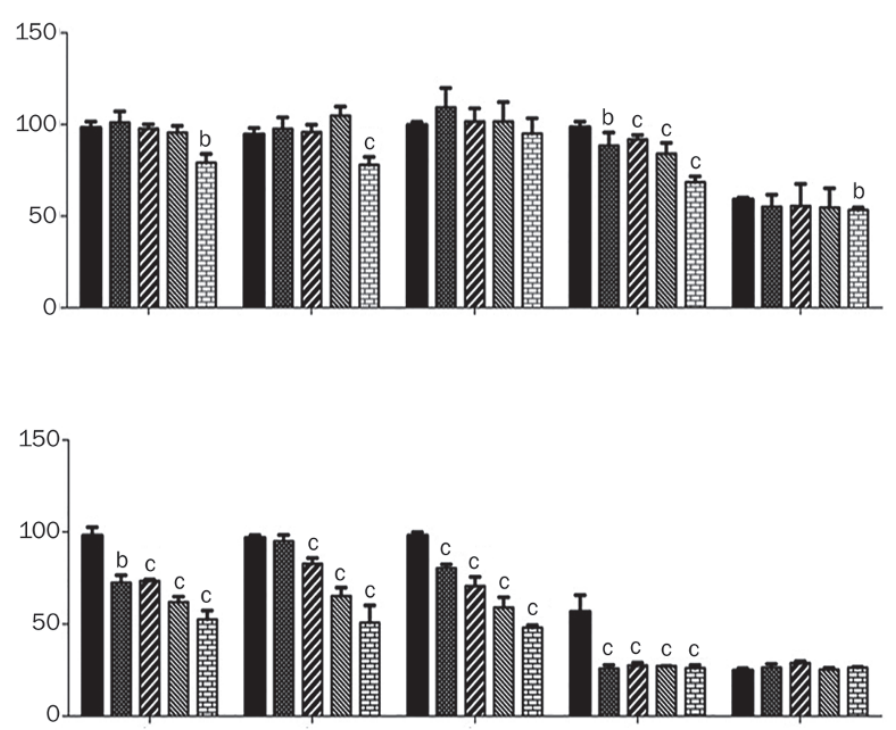
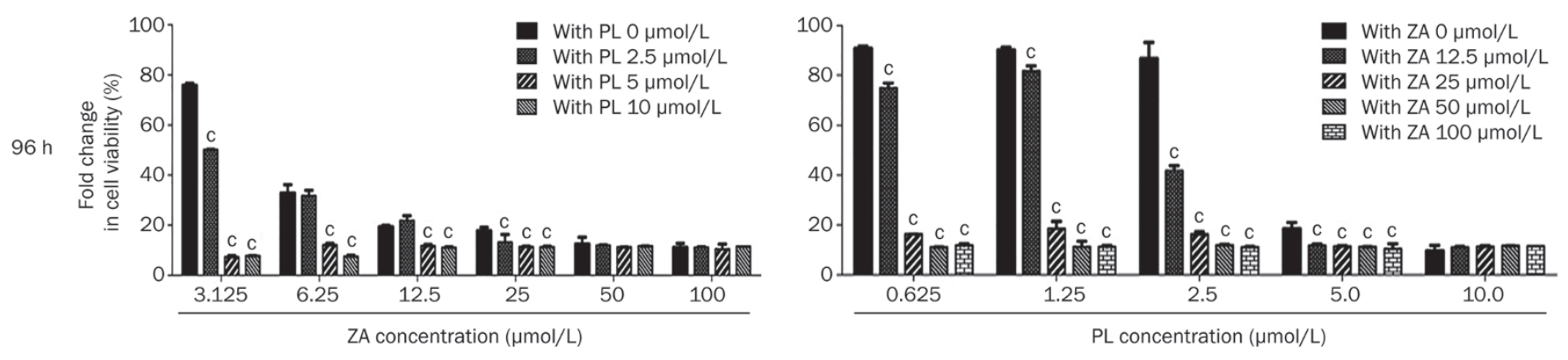

C
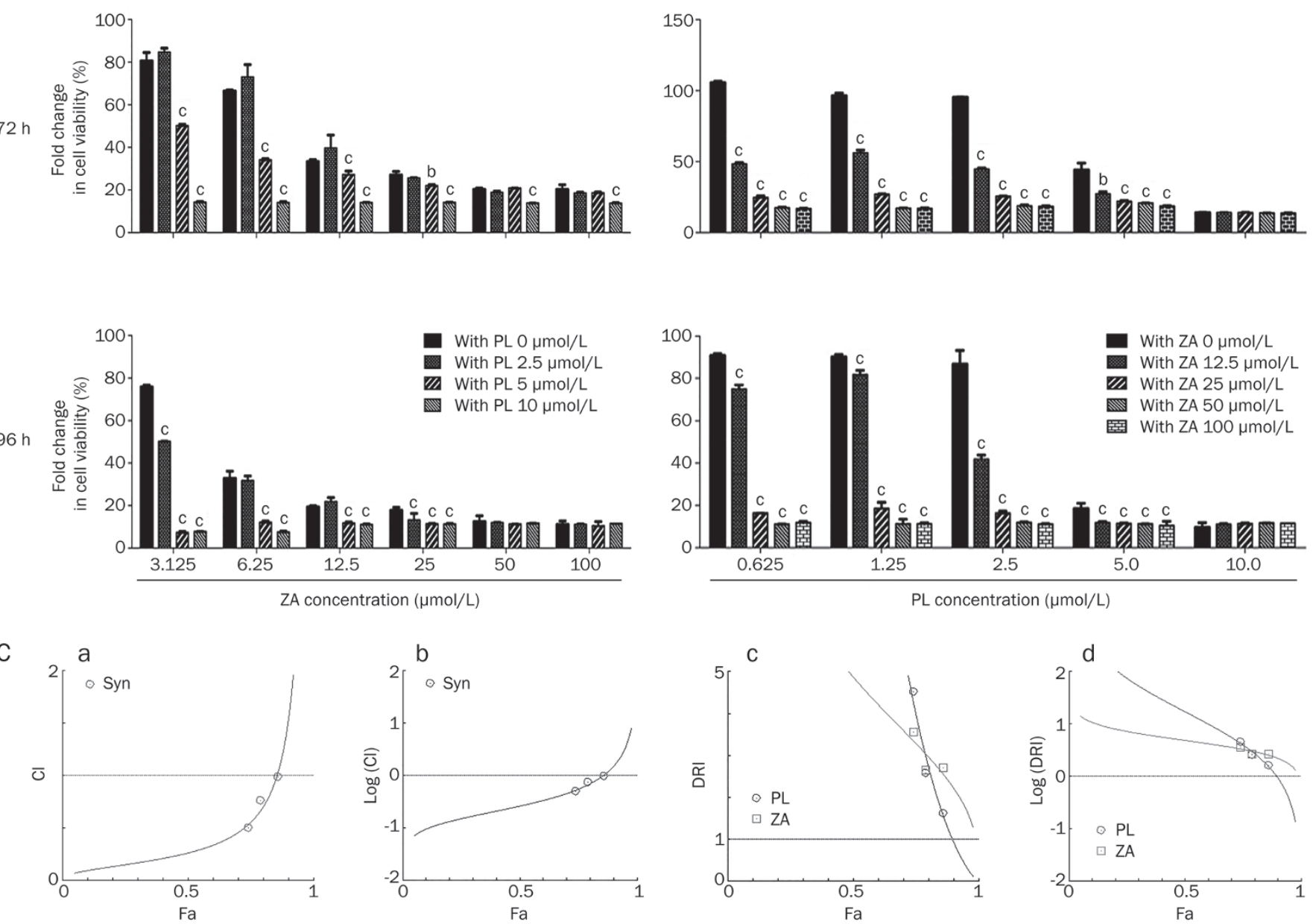

Figure 2. Combined cytotoxic effects of plumbagin (PL) and zoledronic acid (ZA) on MDA-MB-231SArfp breast cancer cells. (A) Combined cytotoxicity after treatment with various ZA concentrations plus $0,2.5,5$, and $10 \mu \mathrm{mol} / \mathrm{L} \mathrm{PL}$ for up to $96 \mathrm{~h}$. (B) Combined cytotoxicity after treatment with various PL concentrations plus 0, 12.5, 25, 50, and $100 \mu \mathrm{mol} / \mathrm{L}$ ZA for up to $96 \mathrm{~h}$. (C) Synergistic analysis is presented with Fa-Cl plot (a), Fa-log (Cl) (b), FaDRI (c), and Fa-log (DRI) plot (d) generated using Compusyn software, with the method based on the median effect principle of Chou and Talalay. All data represent the means \pm SD of at least three independent experiments. ${ }^{b} P<0.05,{ }^{c} P<0.01$. 
apoptotic populations of MDA-MB-231SArfp breast cancer cells (Figure 3). In the PL-treatment group, independent treatments at $2.5,5.0$, and $7.5 \mu \mathrm{mol} / \mathrm{L}$ resulted in total apoptotic rates of $7.5 \% \pm 0.8 \%, 29.7 \% \pm 1.2 \%$, and $35.9 \% \pm 0.8 \%$, respectively. Similarly, the dose-dependent effect observed in the ZAtreatment group demonstrated apoptosis rates of $26.9 \% \pm 0.2 \%$, $33.9 \% \pm 1.3 \%$, and $37.2 \% \pm 1.2 \%$ in the $12.5,25$, and $50 \mu \mathrm{mol} / \mathrm{L}$ groups, respectively. In combination, 5 and $7.5 \mu \mathrm{mol} / \mathrm{L} \mathrm{PL}$ significantly augmented the apoptotic efficacy of 12.5, 25, and $50 \mu \mathrm{mol} / \mathrm{L}$ ZA from $51.3 \% \pm 2.3 \%$ to $78.1 \% \pm 0.8 \%, 59.3 \% \pm 1.3 \%$ to $80.9 \% \pm 2.0 \%$ and $67.5 \% \pm 0.15 \%$ to $84.5 \% \pm 0.4 \%$, respectively. Furthermore, ZA treatment increased the apoptotic potential of PL as well. The rates of apoptosis achieved by 5 and $7.5 \mu \mathrm{mol} / \mathrm{L}$ PL were increased to $51.3 \% \pm 2.3 \%, 59.3 \% \pm 1.2 \%$, and $59.3 \% \pm 1.3 \%$ as well as to $78.1 \% \pm 0.5 \%, 80.9 \% \pm 1.5 \%$, and $84.5 \% \pm 0.4 \%$ with a $\mathrm{ZA}$ treatment range of 12.5 to $50 \mu \mathrm{mol} / \mathrm{L}$. The induction of apoptosis was dose dependent, as demonstrated by the increase in the number of MDA-MB-231SArfp cells in the late stages of apoptosis, indicating that synergism between PL and ZA not only promoted apoptotic cell death but also enhanced the rate of apoptosis.

\section{Inhibition of cell migration via single or combination drug treat- ment}

Treatment with PL and ZA alone or in combination resulted in a dose-dependent decrease in cell migration with respect to the control group (Figure 4). These results indicated that the combination of PL and ZA exhibited a synergistic effect on MDA-MB-231SArfp cell metastasis and led to a significant decrease in the number of cells that penetrated to the bottom membrane of the transwell chamber. Both 25 and $50 \mu \mathrm{mol} / \mathrm{L}$ ZA displayed enhanced synergistic inhibitory ability irrespective of the PL concentration, and this was also demonstrated for $12.5 \mu \mathrm{mol} / \mathrm{L}$ ZA with 2.5 and $5 \mu \mathrm{mol} / \mathrm{L}$ PL. Nevertheless, $12.5 \mu \mathrm{mol} / \mathrm{L}$ ZA exhibited limited synergistic effects in the 10 $\mu \mathrm{mol} / \mathrm{L}$ PL-treatment group. However, 2.5, 5, and $10 \mu \mathrm{mol} / \mathrm{L}$ PL increased the inhibition of tumor metastasis in all ZAtreatment groups. Thus, the metastasis of MDA-MB-231SArfp cells was significantly inhibited through a combination of PL and ZA compared with either agent alone.

\section{Synergistic drug delivery regulated the expression of apoptosis- related proteins}

Based on the above results, we intended to further unravel the underlying mechanisms of the synergistic antitumor effect of PL and ZA. Because synergistic apoptosis regulation was more evident than growth inhibition and because an apoptosis rate of approximately $80 \%$ was achieved after $24 \mathrm{~h}$ with lower drug concentrations, we focused on the mechanisms of apoptosis. Western blot analysis revealed that the expression of t-caspase-3, clv caspase-3, CDKN1A, and ID1 increased in the combination group, whereas the expression of clv PARP, Bcl-2, and Bcl-xL decreased (Figure 5A), indicating the induction of apoptosis through the combination treatment. Because Notch downregulation is often associated with the inhibition of cell viability and the induction of cell apoptosis, real-time PCR was used to evaluate the effects of individual or combined PL and ZA treatment on the Notch signaling pathway in MDAMB-231SArfp cells. As shown in Figure 6A, both PL and synergistic treatment downregulated Notch-1 expression, whereas ZA upregulated Notch-1 mRNA expression compared with the vehicle treatment group. However, the three isoforms of Notch-2/3 failed to exhibit any disparity with respect to the control, especially in the synergism group. Therefore, Western blotting was performed to examine Notch receptor family production at the protein level. Figure 6B shows that Notch-1 protein expression undergoes a similar decrease in the PLand combination-treatment groups and an increase in the ZAtreatment group. Additionally, three bands corresponding to Notch-2 and Notch-3 exhibited only insignificant fluctuations upon Western blot analysis, consistent with reports that Notch-1 downregulation is frequently related to apoptosis induction $^{[36]}$.

\section{DAPT administration decreased $\mathrm{Bcl}-2$ expression}

In addition to the potentiation of multiple apoptotic proteins observed in the synergistic treatment, we observed a similar relationship in the expression of Notch-1 and Bcl-2. Therefore, we conducted a literature search to identify the possibility of reciprocal Notch-1 and Bcl-2 regulation. Ye ${ }^{[43]}$ reported that Notch-1 silencing decreases Bcl-2 protein expression, thereby contributing to a higher rate of apoptosis and an increased sensitivity to docetaxel in PC-3 cells. Thus, we hypothesized that $\mathrm{Bcl}-2$ regulation may be a response to Notch-1 downregulation, especially in the context of combined PL and ZA treatment. Initially, DAPT, which inhibits the $\gamma$-secretase complex of the Notch signaling pathway, was used to inhibit the Notch-1 signaling pathway in MDA-MB-231SArfp breast cancer cells. Upon treatment with a combination of ZA and DAPT or PL, Bcl-2 expression was downregulated (Figure 6D), suggesting that a similar mechanism of Bcl-2 regulation as that induced by PL and DAPT may occur in the synergistic treatment.

\section{Notch-1 silencing increased Bcl-2 expression after synergistic treatment}

To further examine the mechanisms by which changes in Notch-1 and Bcl-2 expression alter apoptosis upon synergistic treatment of PL and ZA, three individual Notch-1 siRNA duplexes were synthesized. To determine the effectiveness of siRNA silencing, RT-PCR and Western blot analyses were performed at 24 and $48 \mathrm{~h}$, respectively, after transfection of Notch-1 siRNA into MDA-MB-231SArfp cells (Figure 7A and 7B). Notch-1 expression was downregulated by siRNA-3916 within $24 \mathrm{~h}$, and all three siRNAs were effective in reducing Notch-1 expression after $48 \mathrm{~h}$ of knockdown, indicating the efficacy of this approach. Because siRNA-3916 exhibited the most efficient mRNA knockdown within $24 \mathrm{~h}$, as well as favorable efficiency at the protein level, this siRNA was applied in further experiments.

As shown in Figure 7D, Bcl-2 expression was lower in the PL-treatment group without siRNA silencing than in the PL- 
A
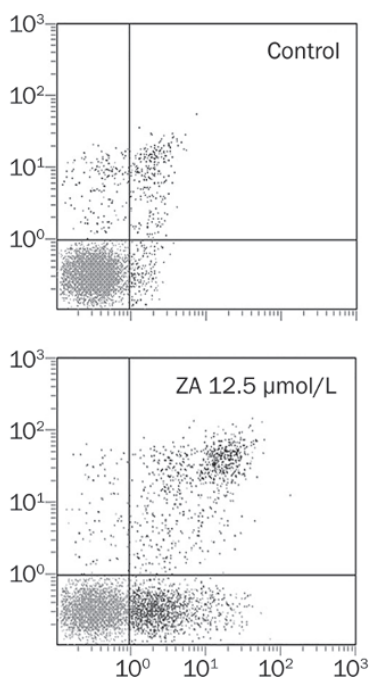
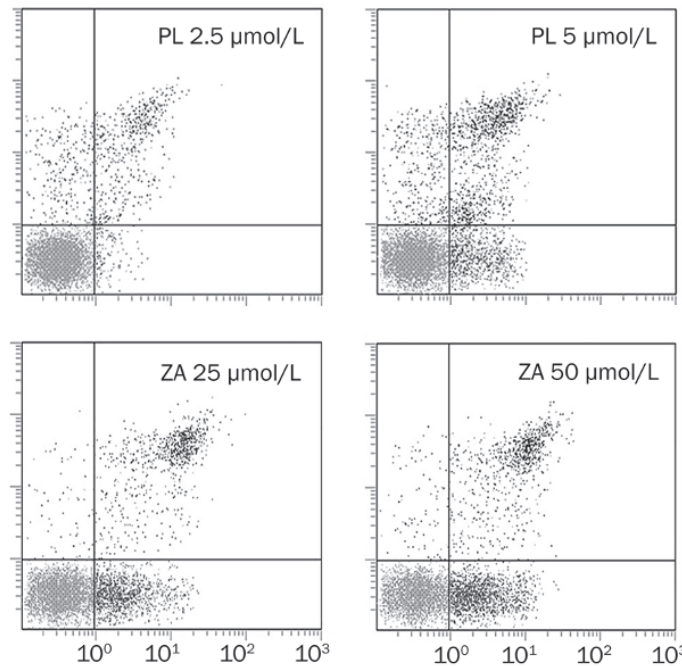

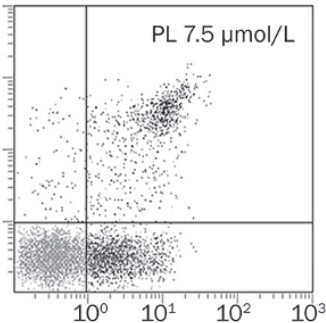

B
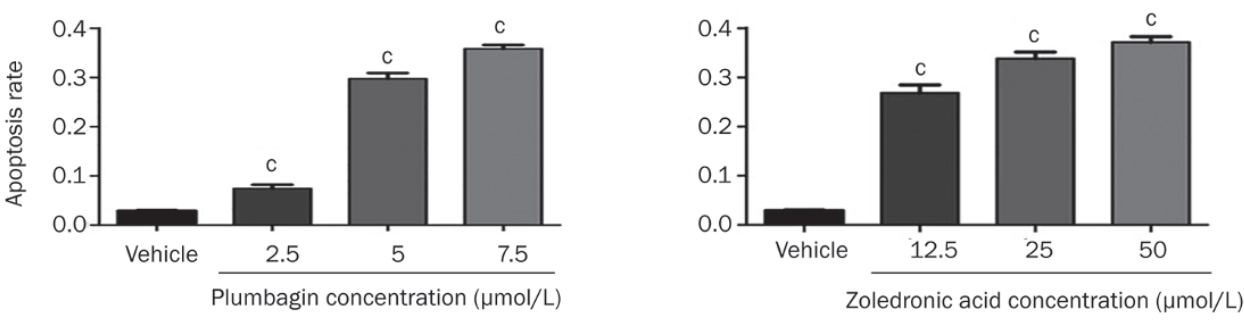

C

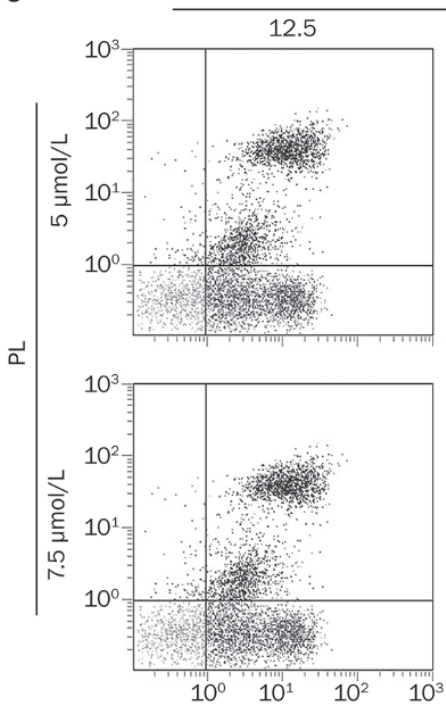

$\mathrm{ZA}(\mu \mathrm{mol} / \mathrm{L})$
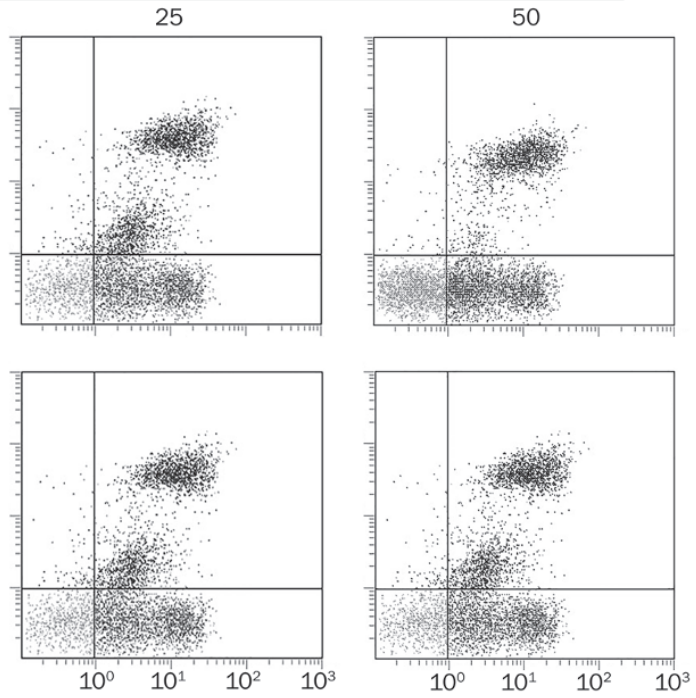

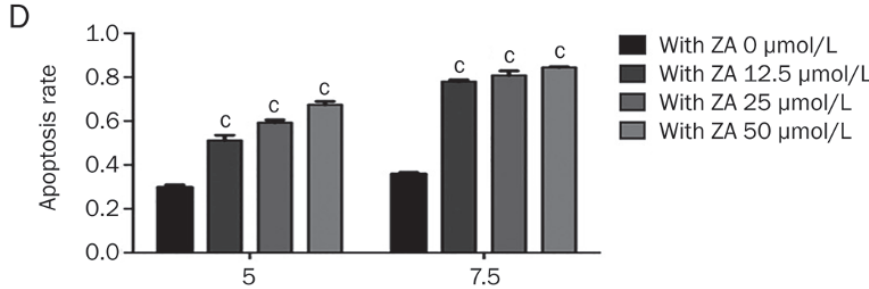

Plumbagin concentration $(\mu \mathrm{mol} / \mathrm{L})$

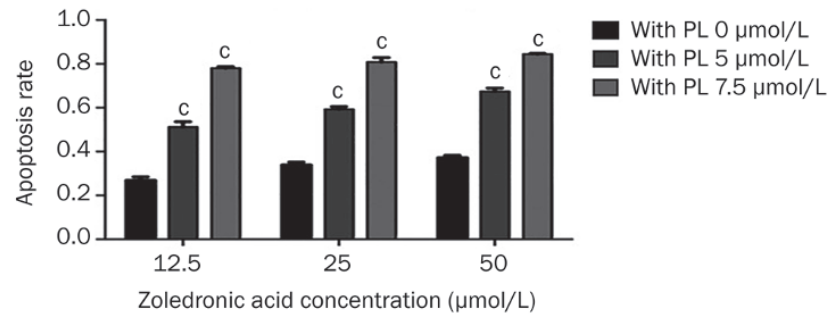

Figure 3. Cell apoptosis induced in MDA-MB-231SArfp cells by plumbagin and zoledronic acid alone or in combination. (A, B) MDA-MB-231SArfp cells were incubated with the indicated concentrations of PL and ZA alone for $24 \mathrm{~h}$, followed by annexin V-FITC/PI double staining to evaluate apoptotic cell death. (C, D) Similar procedures were performed in MDA-MB-231SArfp cells after combined treatment with PL and ZA for $24 \mathrm{~h}$. All data represent the mean $\pm S D$ of at least three independent experiments. ${ }^{c} P<0.01$ vs vehicle. 
A

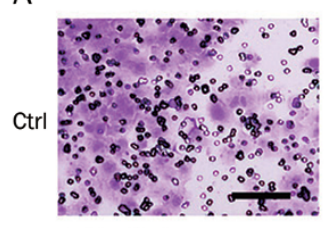

C

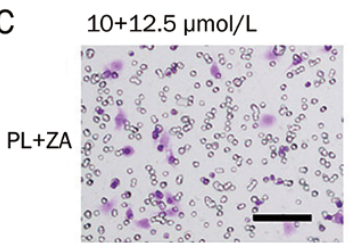

$10+25 \mu \mathrm{mol} / \mathrm{L}$

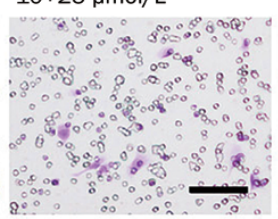

$10+50 \mu \mathrm{mol} / \mathrm{L}$

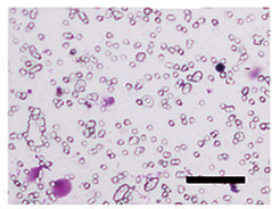

$5+25 \mu \mathrm{mol} / \mathrm{L}$
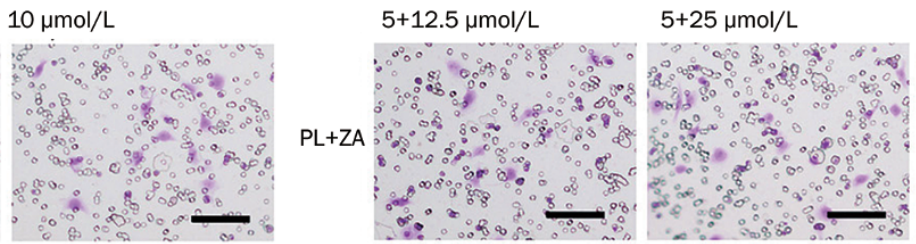

$5+50 \mu \mathrm{mol} / \mathrm{L}$
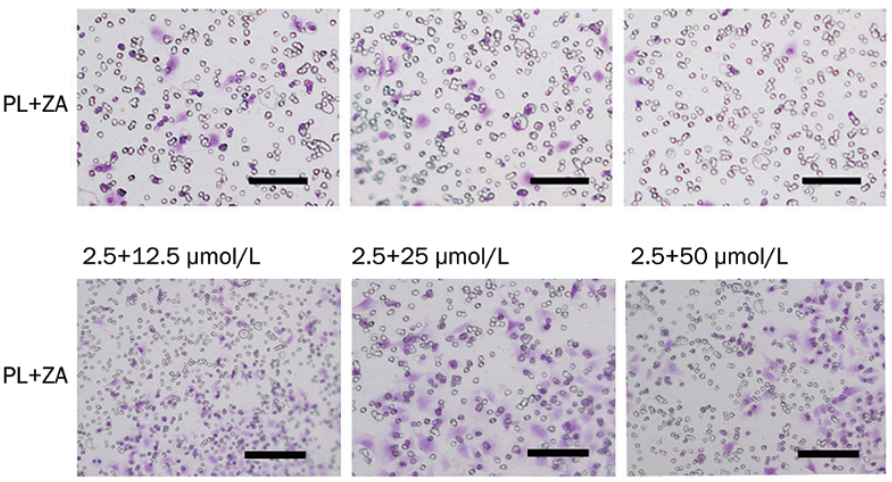

$2.5+25 \mu \mathrm{mol} / \mathrm{L}$

$50 \mu \mathrm{mol} / \mathrm{L}$

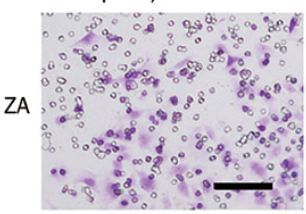

$25 \mu \mathrm{mol} / \mathrm{L}$
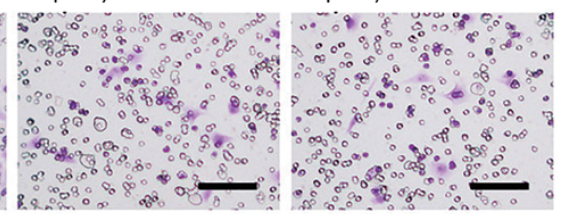

B
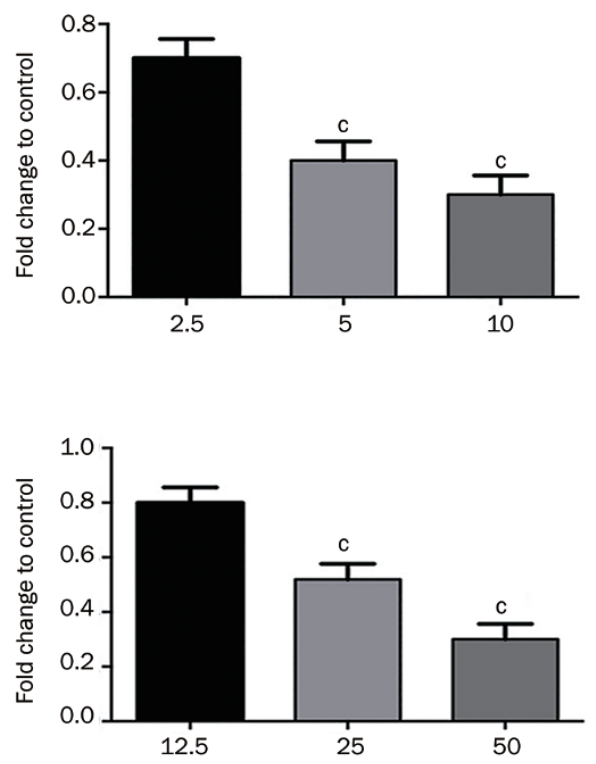

D
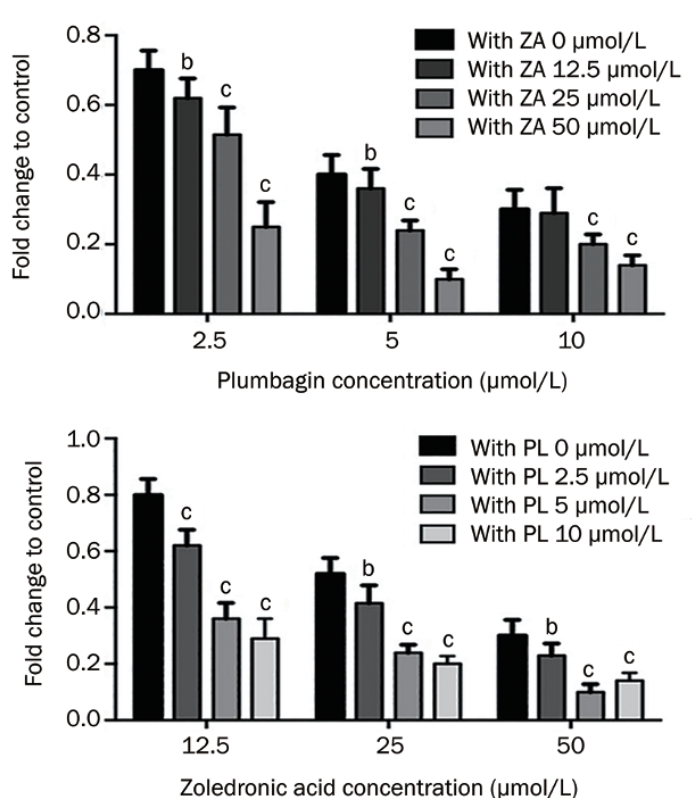

Figure 4. Effects of plumbagin(PL) and zoledronic acid (ZA) alone or in combination on MDA-MB-231SArfp cell migration. (A, B) In vitro evaluation of MDA-MB-231SArfp cell migration after PL and ZA treatment alone. (C, D) Combined administration of PL and ZA significantly enhances the inhibition of tumor cell metastasis compared with individual treatment. All data represent the means $\pm S D$ of at least three independent experiments. ${ }^{b} P<0.05$, ${ }^{\mathrm{c}} \mathrm{P}<0.01$.

with-siRNA group. Additionally, treatment after siRNA silencing upregulated Bcl-2 expression compared with synergistic treatment alone, indicating that knocking down Notch-1 may result in the upregulation of Bcl-2 after combination treatment. The presence of Notch-1 promoted the downstream regulation of Bcl-2 and induced subsequent apoptosis enhancement after synergistic treatment. Thus, we demonstrated that synergistic suppression of Notch-1 signaling decreased the downstream, ZA-mediated expression of Bcl-2 and potentiated the apoptosis induced by the synergistic treat- ment (Figure 8).

\section{Discussion}

In this study, PL was able to serve as an efficient adjuvant reagent in sensitizing ZA-mediated cell growth inhibition, apoptosis activation and metastasis suppression; this result was supported by the activation of CDKN1A, clv caspase-3 and PARP and the inactivation of Bcl-2 and Bcl-xl. Furthermore, we revealed the underlying mechanisms of apoptotic potentiation, which involves Notch-1-to-Bcl-2 regulation upon 
A

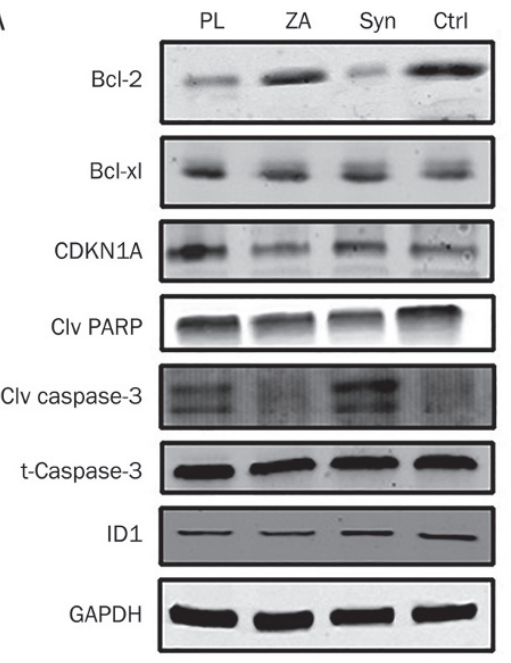

B
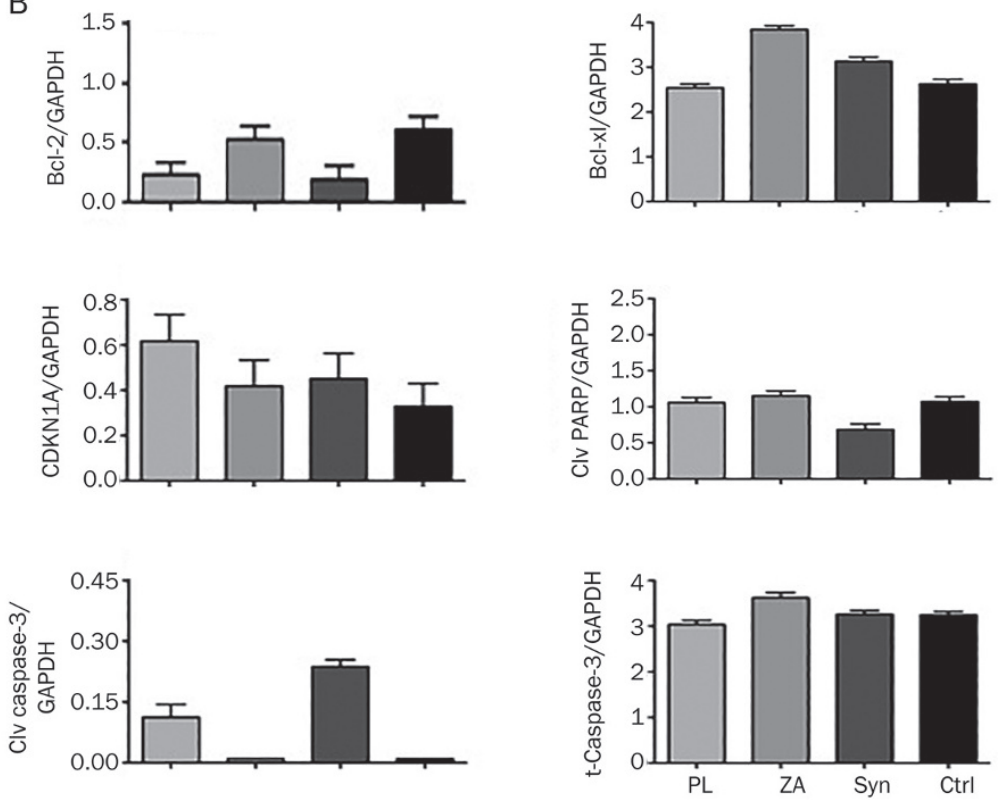

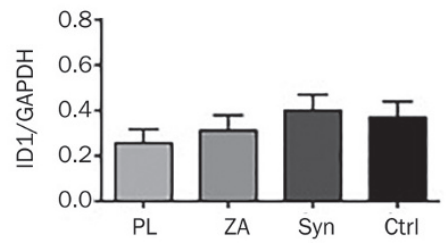

Figure 5. Analysis of apoptosis-associated protein expression in MDA-MB-231SArfp cells. MDA-MB-231SArfp cells were treated with PL and ZA, either alone or in combination, or with vehicle control. Protein extracts were immunoblotted to determine the relative expression of apoptosis-associated proteins, including Bcl-2, Bcl-xl, CDKN1A, clv PARP, clv caspase 3, t-caspase 3, and ID1 (A). Protein expression levels (relative to GAPDH) were calculated $(B)$. All data represent the means $\pm S D$ of at least three independent experiments.

synergistic treatment with PL and ZA.

When evaluating cell growth inhibition, we observed that only relatively high concentrations of PL and ZA alone exhibited cytotoxicity against MDA-MB-231SArfp cells in the first $24 \mathrm{~h}$. However, PL exhibited a synergistic effect with ZA in MDA-MB-231SArfp cells, with a CI value of 0.26 . The DRI value also indicated a synergistic effect between PL and ZA, with actual values of 5.52 and 3.59, respectively, thus demonstrating accelerated inhibitory effects through the combination of PL and ZA. Additionally, we observed increased treatment efficacy with respect to synergism-induced cell growth inhibition in a time- and dose-dependent manner. However, the synergistic effect displayed no significant differences at $96 \mathrm{~h}$ using 50 or $100 \mu \mathrm{mol} / \mathrm{L} \mathrm{ZA}$ or at 48,72 , or $96 \mathrm{~h}$ using 10 $\mu \mathrm{mol} / \mathrm{L}$ PL with adjuvant agents at any concentration. This phenomenon can be readily explained by the fact that the cell viability rates of 50 and $100 \mu \mathrm{mol} / \mathrm{L} \mathrm{ZA}$ at $96 \mathrm{~h}$, as well as 10 $\mu \mathrm{mol} / \mathrm{L}$ PL at 48 to $96 \mathrm{~h}$, were approximately $10 \%$ relative to the control group. Therefore, it would be extremely difficult to further reduce the extent of cell growth suppression regardless of synergistic treatment.

Based on the above results, we further observed the beneficial induction of cell apoptosis when cells were exposed to lower concentrations of PL and ZA, which produced a dramatic increase in the apoptotic cell number compared with single-drug administration. The induction of apoptosis was also time and dose dependent, with a maximum apoptotic rate of approximately $80 \%$ when cells were treated with $7.5 \mu \mathrm{mol} / \mathrm{L}$ PL and $50 \mu \mathrm{mol} / \mathrm{L} \mathrm{ZA}$. This result suggests the potential of using lower ZA concentrations with nontoxic PL doses to achieve an enhanced level of effectiveness with respect to tumor cell apoptosis. This approach may also reduce the drug-related toxic side effects to normal cells and inhibit the evolution of chemoresistance to ZA and PL.

We also investigated the in vitro suppression of MDA-MB231SArfp cell metastasis through synergistic treatment with PL and ZA. Greater inhibition of cell migration was observed when tumor cells were treated with a combination of PL and $\mathrm{ZA}$, indicating that $\mathrm{PL}$ is able to reinforce the suppressive effect of ZA. Previous studies have revealed that both PL and $Z A$ alone can be effective in inhibiting cell metastasis ${ }^{[29,44]}$, and our results demonstrate that the combination of PL and ZA exhibited greater efficacy in inhibiting breast cancer metastasis compared with either PL or ZA alone.

Because the regulation of synergistic apoptosis was more evident than growth inhibition at lower effective drug con- 

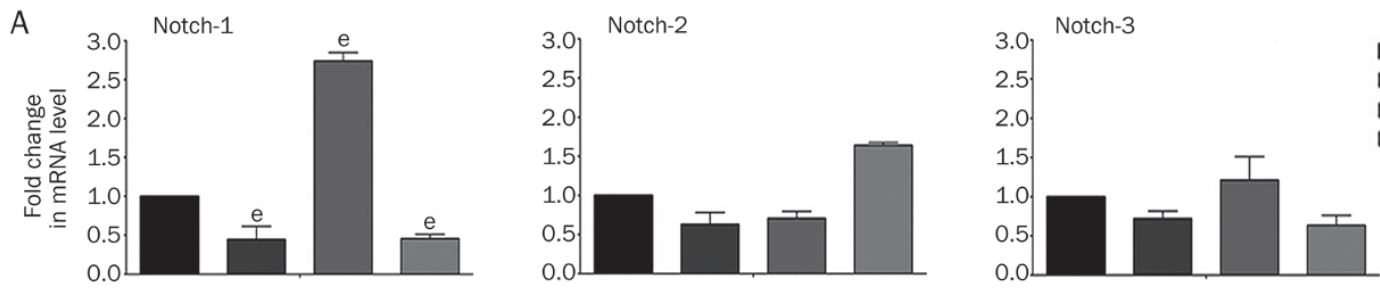
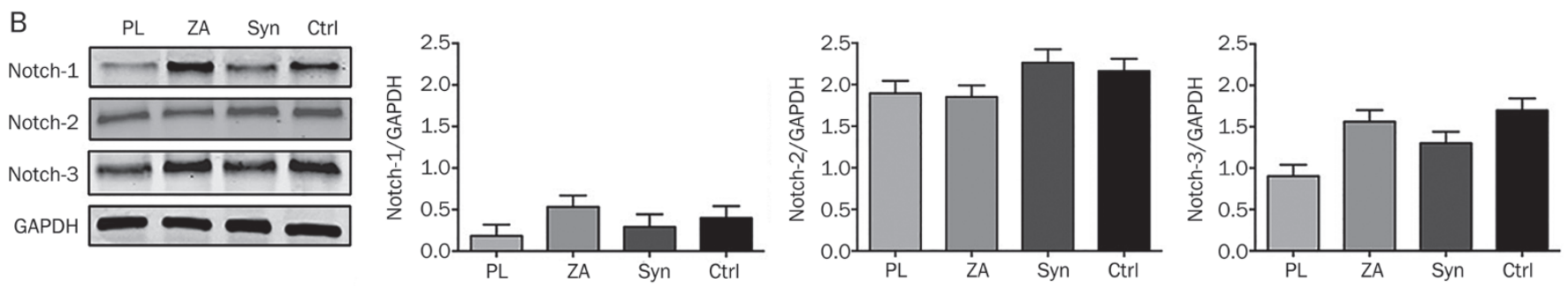
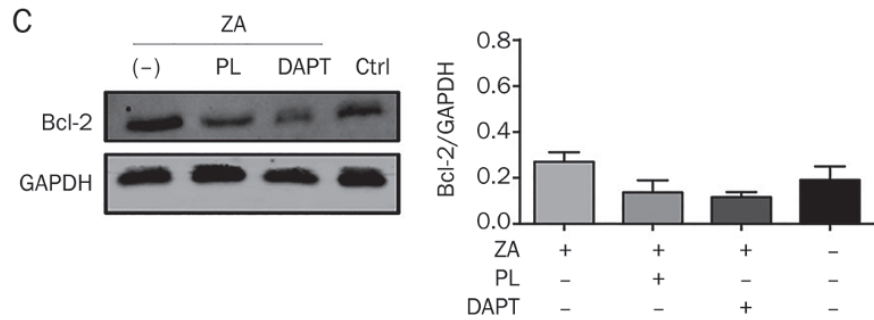

Figure 6. Notch receptor and Bcl-2 expression after drug and DAPT administration. (A) Real-time PCR demonstrated that Notch-1 expression decreased in the $\mathrm{PL}$ and combination group but increased in the ZA group, irrespective of the insignificant fluctuation of Notch-2/3 expression. (B, C) Western blotting revealed similar alterations in Notch receptor expression with the different treatments. (D, E) Compared with ZA treatment alone, Bcl-2 expression decreased upon treatment with ZA plus PL and DAPT, likely indicating a similar mechanism of action between PL and DAPT combined with ZA. ${ }^{e}$ Indicates at least a two-fold mRNA change relative to the control group. $n=3$. Protein expression levels (relative to GAPDH) were calculated. All data represent the means $\pm \mathrm{SD}$ of at least three separate experiments.

centrations after $24 \mathrm{~h}$, we chose to investigate the apoptosis mechanisms. Our results revealed that Notch-1 down-regulation by synergistic treatment was associated with higher rates of apoptosis. Because apoptosis inevitably involves caspase activation, the expression of caspase-3, which serves as the key effector of the caspase cascade, was evaluated. After $24 \mathrm{~h}$ of treatment, the total level of caspase-3 did not vary among the four groups, whereas the cleaved form was significantly higher in the synergistic-treatment group relative to that of the control, indicating greater caspase-3 bioactivity and enhanced apoptotic capability. PARP cleavage is another hallmark of apoptosis and was also investigated. A slight down-regulation of PARP cleavage was noted with either PL or ZA treatment alone, whereas an obvious decrease was observed upon synergistic treatment compared with the control. CDKN1A/ p21 serves as a novel Notch downstream target and plays an essential role in growth inhibition and cell cycle arrest ${ }^{[45-47]}$. Our results demonstrated that combined administration of PL and ZA appeared to increase the expression of p21, which was expressed at low levels in the ZA-treatment group, thus promoting the enhanced apoptosis of MDA-MB-231SArfp cells.

A previous study ${ }^{[43]}$ revealed that $\mathrm{Bcl}-2$ expression is down- regulated by Notch-1 knockdown, which leads to an increase in apoptosis and a decrease in the proliferation of tumor cells. Therefore, we hypothesized that synergistic apoptotic potentiation may partially be caused by the combined inactivation of Notch-1 and Bcl-2, which results in the collapse of the tumor defense mechanism. Thus, we used DAPT, a non-specific Notch signaling pathway inhibitor, to simulate the probable mechanism of PL when administered with ZA. Consistent with previous results, Bcl-2 expression decreased significantly when cells were given PL and ZA together compared with ZA alone. Additionally, when MDA-MB-231SArfp cells were treated with ZA and DAPT, a significant suppression of Bcl-2 was observed, which resembled that of the PL-and-ZAtreatment group. These results suggest that the underlying mechanism of Bcl-2 suppression may be caused by the synergistic downregulation of the Notch signaling pathway, as shown by the combined effect of ZA and DAPT. Therefore, a specific siRNA was designed to knock down Notch-1 expression in MDA-MB-231SArfp cells. The results suggest that synergistic PL and ZA treatment followed by siRNA silencing might contribute to the potentiated expression of Bcl-2 due to the absence of Bcl-2 regulation by Notch-1. Subsequently, 
A

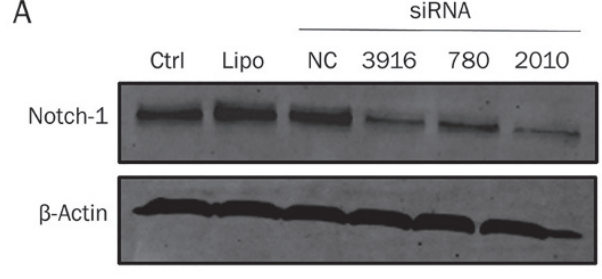

B

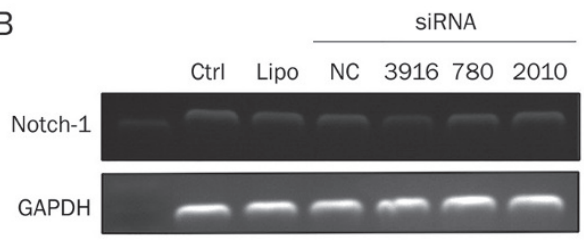

D
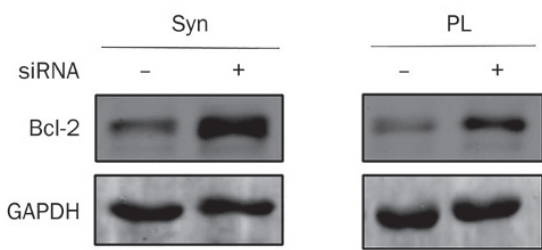

C

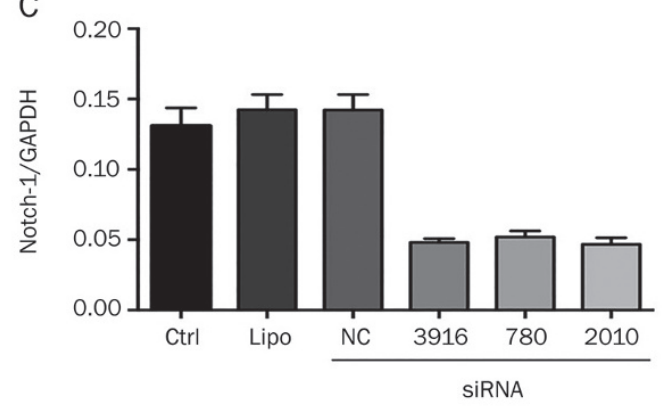

E

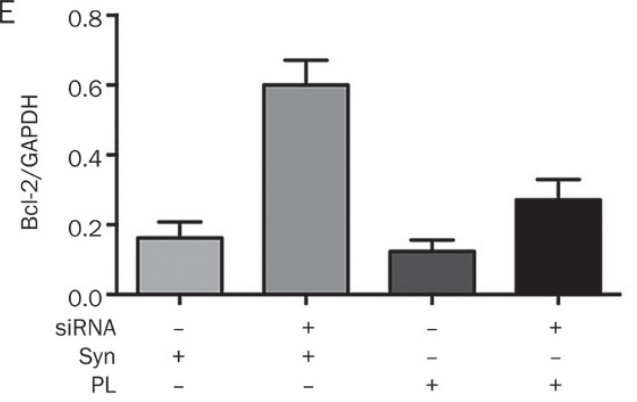

Figure 7. siRNA against Notch-1 and subsequent Bcl-2 expression alteration after combined reagent treatment. (A, B, and C) Specific siRNA silencing of Notch-1. RT-PCR and Western blotting were used to evaluate the efficacy of this approach. (D, E) MDA-MB-231SArfp cells were treated with the indicated agents after specific siRNA-3916 silencing against Notch-1. Both the combination and individual PL treatments resulted in increased Bcl-2 expression compared with the non-siRNA group, suggesting that the absence of upstream Notch-1 inhibition may lead to increased Bcl-2 production after the combination treatment. Protein expression levels (relative to GAPDH) were calculated. All data represent the means \pm SD of at least three separate experiments.

because PL was able to reduce the expression of Bcl-2 when administered with ZA, we used siRNA to verify whether the Notch-1-to-Bcl-2 regulation also occurred in cells treated with PL alone. We determined that Bcl-2 expression increased with PL administration alone when siRNA silencing was included. Thus, the drug-induced suppression of Bcl-2 regulation by Notch-1 was eliminated by siRNA silencing, which led to increased Bcl-2 expression after the combination treatment. Therefore, our results confirmed that the elevated apoptosis of MDA-MB-231SArfp cells induced by synergistic administration of PL and ZA was associated with decreased levels of Notch-1 and Bcl-2. Moreover, a latent connection between Notch-1 and Bcl-2 is perceived to be of significance in this synergistic apoptosis-induction effect.

Our study is the first to unravel the underlying Notch-1-Bcl2 regulation in the synergistic condition and shows the potent efficacy of enhancing commonly used clinical drugs with plumbagin, thus providing a convincing direction for future drug treatment strategies. Because ZA is supposed to exhibit a high affinity to mineralized bone matrix, such as hydroxyapatite in bone tissues ${ }^{[48]}$, further bone-targeted administration of PL conjugated with ZA would be an attractive strategy for treating bone metastases of breast cancer. Certain polymeric nanoparticles or combinations with BP have been reported to provide effective delivery to cells in vitro ${ }^{[49]}$ or bone tissue in vivo ${ }^{[50]}$.
In conclusion, we observed that PL synergized the cytotoxicity, apoptotic induction and metastatic suppression induced by ZA in MDA-MB-231SArfp human breast cancer cells. More importantly, our findings demonstrate that PL can inhibit the ZA-induced activation of the Notch-1 signaling pathway and subsequently reduce the downstream expression of $\mathrm{Bcl}-2$, thus potentiating the execution of apoptosis caused by the synergism between PL and ZA.

\section{Acknowledgements}

This work was supported by grants from the National Natural Science Foundation of China (№ 81172549 and 81301531) and the Shanghai Science and Technology Development Fund (№ 13DZ2294000).

\section{Author contribution}

Han QIAO, Ting-yu WANG, Wei YAN, An QIN, and Tingting TANG designed the experiments; Han QIAO, Ting-yu WANG, Xiu-guo HAN, and Yu-gang WANG performed the research; Han QIAO, An QIN, Qi-ming FAN, and Ting-ting TANG analyzed the data; Han QIAO, Ting-yu WANG, and Ting-ting TANG wrote the paper.

\section{References}

1 Lipton A, Theriault RL, Hortobagyi GN, Simeone J, Knight RD, Mellars $\mathrm{K}$, et al. Pamidronate prevents skeletal complications and is effective 
<smiles>CC1=CC(=O)c2c(O)cccc2C1=O</smiles><smiles>O=P(O)(O)C(O)(Cn1ccnc1)P(=O)(O)O</smiles>
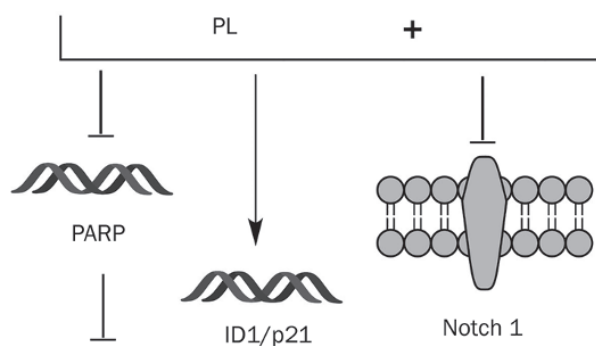

ZA
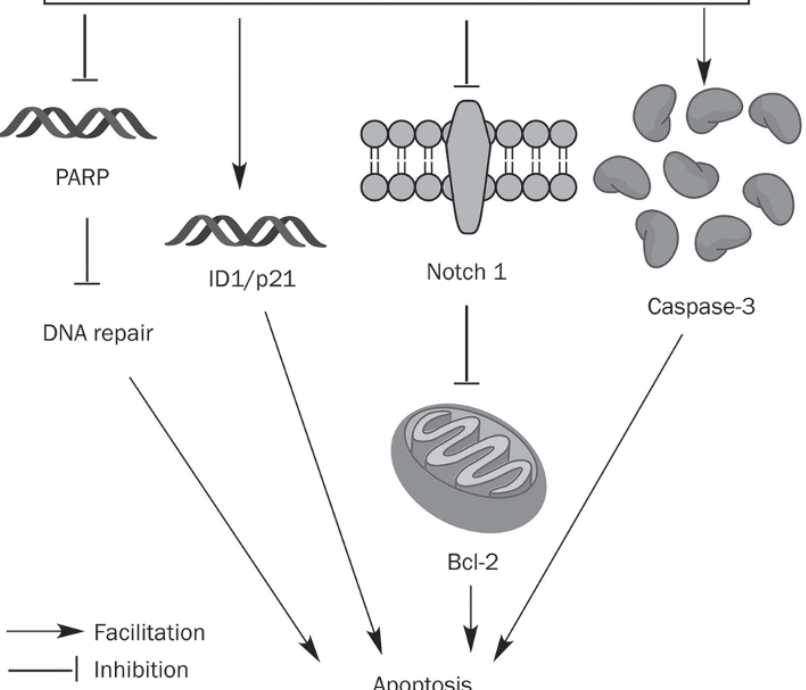

Caspase-3

Figure 8. A schematic diagram of the proposed mechanisms of MDAMB-231SArfp breast cancer cell apoptosis by synergistic treatment with plumbagin $(\mathrm{PL})$ and zoledronic acid $(\mathrm{ZA})$. According to the results of the present study, combined treatment with $\mathrm{PL}$ and $\mathrm{ZA}$ facilitates the expression of ID1, p21 (CDKN1A), cleaved caspase 3 while inhibiting the production of PARP and Notch-1, which contributes to decreased levels of $\mathrm{Bcl}-2$ and results in the overall potentiation of apoptosis.

palliative treatment in women with breast carcinoma and osteolytic bone metastases: long term follow-up of two randomized, placebocontrolled trials. Cancer 2000; 88: 1082-90.

2 Rose AA, Siegel PM. Breast cancer-derived factors facilitate osteolytic bone metastasis. Bull Cancer 2006; 93: 931-43.

3 Hughes DE, MacDonald BR, Russell RG, Gowen M. Inhibition of osteoclast-like cell formation by bisphosphonates in long-term cultures of human bone marrow. J Clin Invest 1989; 83: 1930-5.

4 Sahni M, Guenther HL, Fleisch H, Collin P, Martin TJ. Bisphosphonates act on rat bone resorption through the mediation of osteoblasts. J Clin Invest 1993; 91: 2004-11.

5 Carano A, Teitelbaum SL, Konsek JD, Schlesinger PH, Blair HC. Bisphosphonates directly inhibit the bone resorption activity of isolated avian osteoclasts in vitro. J Clin Invest 1990; 85: 456-61.

6 Murakami H, Takahashi N, Sasaki T, Udagawa N, Tanaka S, Nakamura I, et al. A possible mechanism of the specific action of bisphosphonates on osteoclasts: tiludronate preferentially affects polarized osteoclasts having ruffled borders. Bone 1995; 17: 137-44.

7 Yu X, Scholler J, Foged NT. Interaction between effects of parathyroid hormone and bisphosphonate on regulation of osteoclast activity by the osteoblast-like cell line UMR-106. Bone 1996; 19: 339-45.

8 Insalaco L, Di Gaudio F, Terrasi M, Amodeo V, Caruso S, Corsini LR, et al. Analysis of molecular mechanisms and anti-tumoural effects of zoledronic acid in breast cancer cells. J Cell Mol Med 2012; 16:

2186-95.

9 Jagdev SP, Coleman RE, Shipman CM, Rostami HA, Croucher PI. The bisphosphonate, zoledronic acid, induces apoptosis of breast cancer cells: evidence for synergy with paclitaxel. Br J Cancer 2001; 84: 1126-34.

10 Fromigue 0, Lagneaux L, Body JJ. Bisphosphonates induce breast cancer cell death in vitro. J Bone Miner Res 2000; 15: 2211-21.

11 Mathew A, Brufsky A. Bisphosphonates in breast cancer. Int J Cancer 2015; 137: 753-64.

12 Kiper HD, Tezcanli Kaymaz B, Gokbulut AA, Selvi N, Avci CB, Kosova $\mathrm{B}$, et al. STAT pathway in the regulation of zoledronic acid-induced apoptosis in chronic myeloid leukemia cells. Biomed Pharmacother 2013; 67: 527-32.

13 Wang IT, Chou SC, Lin YC. Zoledronic acid induces apoptosis and autophagy in cervical cancer cells. Tumour Biol 2014; 35: 11913-20.

14 Ge XY, Yang LQ, Jiang Y, Yang WW, Fu J, Li SL. Reactive oxygen species and autophagy associated apoptosis and limitation of clonogenic survival induced by zoledronic acid in salivary adenoid cystic carcinoma cell line SACC-83. PLoS One 2014; 9: e101207.

15 Horie N, Murata H, Kimura S, Takeshita H, Sakabe T, Matsui T, et al. Combined effects of a third-generation bisphosphonate, zoledronic acid with other anticancer agents against murine osteosarcoma. $\mathrm{Br} \mathrm{J}$ Cancer 2007; 96: 255-61.

16 Ibrahim T, Liverani C, Mercatali L, Sacanna E, Zanoni M, Fabbri F, et al. Cisplatin in combination with zoledronic acid: a synergistic effect in triple-negative breast cancer cell lines. Int J Oncol 2013; 42: 1263-70.

17 Luo KW, Ko CH, Yue GG, Gao S, Lee JK, Li G, et al. The combined use of Camellia sinensis and metronomic zoledronic acid in a breast cancer-induced osteolysis mouse model. J Cancer Res Clin Oncol 2015;141: 1025-36.

18 Stresing V, Daubine F, Benzaid I, Monkkonen H, Clezardin P. Bisphosphonates in cancer therapy. Cancer Lett 2007; 257: 16-35.

19 Dos Santos MP, de Farias CB, Roesler R, Brunetto AL, Abujamra AL. In vitro antitumor effect of sodium butyrate and zoledronic acid combined with traditional chemotherapeutic drugs: a paradigm of synergistic molecular targeting in the treatment of Ewing sarcoma. Oncol Rep 2014; 31: 955-68.

20 Yu Y, Song Z, Yang S, Yang X, Zhang J, Lu S. Everolimus and zoledronic acid - a potential synergistic treatment for lung adenocarcinoma bone metastasis. Acta Biochim Biophys Sin 2014; 46: 792-801.

21 de Paiva SR, Figueiredo MR, Aragao TV, Kaplan MA. Antimicrobial activity in vitro of plumbagin isolated from Plumbago species. Mem Inst Oswaldo Cruz 2003; 98: 959-61.

22 Sharma I, Gusain D, Dixit VP. Hypolipidaemic and antiatherosclerotic effects of plumbagin in rabbits. Indian J Physiol Pharmacol 1991; 35: 10-4.

23 Checker R, Sharma D, Sandur SK, Khanam S, Poduval TB. Antiinflammatory effects of plumbagin are mediated by inhibition of NFkappaB activation in Iymphocytes. Int Immunopharmacol 2009; 9: 949-58.

24 Aziz MH, Dreckschmidt NE, Verma AK. Plumbagin, a medicinal plant-derived naphthoquinone, is a novel inhibitor of the growth and invasion of hormone-refractory prostate cancer. Cancer Res 2008; 68: 9024-32.

25 Sand JM, Bin Hafeez B, Jamal MS, Witkowsky O, Siebers EM, Fischer J, et al. Plumbagin (5-hydroxy-2-methyl-1,4-naphthoquinone), isolated from Plumbago zeylanica, inhibits ultraviolet radiation-induced development of squamous cell carcinomas. Carcinogenesis 2012; 33: 184-90.

26 Kuo PL, Hsu YL, Cho CY. Plumbagin induces $\mathrm{G}_{2}-\mathrm{M}$ arrest and 
autophagy by inhibiting the AKT/mammalian target of rapamycin pathway in breast cancer cells. Mol Cancer Ther 2006; 5: 3209-21.

27 Sandur SK, Ichikawa H, Sethi G, Ahn KS, Aggarwal BB. Plumbagin (5-hydroxy-2-methyl-1,4-naphthoquinone) suppresses NF-kappaB activation and NF-kappaB-regulated gene products through modulation of p65 and IkappaBalpha kinase activation, leading to potentiation of apoptosis induced by cytokine and chemotherapeutic agents. J Biol Chem 2006; 281: 17023-33.

28 Yan W, Wang TY, Fan QM, Du L, Xu JK, Zhai ZJ, et al. Plumbagin attenuates cancer cell growth and osteoclast formation in the bone microenvironment of mice. Acta Pharmacol Sin 2014; 35: 124-34.

29 Yan W, Tu B, Liu YY, Wang TY, Qiao H, Zhai ZJ, et al. Suppressive effects of plumbagin on invasion and migration of breast cancer cells via the inhibition of STAT3 signaling and down-regulation of inflammatory cytokine expressions. Bone Res 2013; 1: 362-70.

30 Logothetis $\mathrm{CJ}$, Lin SH. Osteoblasts in prostate cancer metastasis to bone. Nat Rev Cancer 2005; 5: 21-8.

31 Miele L. Notch signaling. Clin Cancer Res 2006; 12: 1074-9.

32 Miele L, Golde T, Osborne B. Notch signaling in cancer. Curr Mol Med 2006; 6: 905-18.

33 Chadwick N, Zeef L, Portillo V, Fennessy C, Warrander F, Hoyle S, et al. Identification of novel Notch target genes in T cell leukaemia. Mol Cancer 2009; 8: 35.

34 Parr C, Watkins G, Jiang WG. The possible correlation of Notch-1 and Notch-2 with clinical outcome and tumour clinicopathological parameters in human breast cancer. Int J Mol Med 2004; 14: 779-86.

35 Bin Hafeez B, Adhami VM, Asim M, Siddiqui IA, Bhat KM, Zhong W, et al. Targeted knockdown of Notch1 inhibits invasion of human prostate cancer cells concomitant with inhibition of matrix metalloproteinase-9 and urokinase plasminogen activator. Clin Cancer Res 2009; 15 : 452-9.

36 Wang Z, Li Y, Banerjee S, Kong D, Ahmad A, Nogueira V, et al. Downregulation of Notch-1 and Jagged-1 inhibits prostate cancer cell growth, migration and invasion, and induces apoptosis via inactivation of Akt, mTOR, and NF-kappaB signaling pathways. J Cell Biochem 2010; 109: 726-36.

37 Yoneda T, Williams PJ, Hiraga T, Niewolna M, Nishimura R. A boneseeking clone exhibits different biological properties from the MDAMB-231 parental human breast cancer cells and a brain-seeking clone in vivo and in vitro. J Bone Miner Res 2001; 16: 1486-95.

38 Price JT, Quinn JM, Sims NA, Vieusseux J, Waldeck K, Docherty SE, et al. The heat shock protein 90 inhibitor, 17-allylamino-17-demethoxy- geldanamycin, enhances osteoclast formation and potentiates bone metastasis of a human breast cancer cell line. Cancer Res 2005; 65: 4929-38.

39 Yan C, Zhu Y, Zhang X, Chen X, Zheng W, Yang J. Down-regulated aquaporin 5 inhibits proliferation and migration of human epithelial ovarian cancer 3 AO cells. J Ovarian Res 2014; 7: 78.

40 Chou TC. Preclinical versus clinical drug combination studies. Leuk Lymphoma 2008; 49: 2059-80.

41 Chou TC, Talalay P. Quantitative analysis of dose-effect relationships: the combined effects of multiple drugs or enzyme inhibitors. Adv Enzyme Regul 1984; 22: 27-55.

42 Zhao L, Wientjes MG, Au JL. Evaluation of combination chemotherapy: integration of nonlinear regression, curve shift, isobologram, and combination index analyses. Clin Cancer Res 2004; 10: 7994-8004.

43 Ye QF, Zhang YC, Peng XQ, Long Z, Ming YZ, He LY. Silencing Notch-1 induces apoptosis and increases the chemosensitivity of prostate cancer cells to docetaxel through Bcl-2 and Bax. Oncol Lett 2012; 3: 879-84.

44 Singh T, Kaur V, Kumar M, Kaur P, Murthy RS, Rawal RK. The critical role of bisphosphonates to target bone cancer metastasis: an overview. J Drug Target 2015; 23: 1-15.

45 Niculescu AB 3rd, Chen X, Smeets M, Hengst L, Prives C, Reed SI. Effects of p21 (Cip1/Waf1) at both the $\mathrm{G}_{1} / \mathrm{S}$ and the $\mathrm{G}_{2} / \mathrm{M}$ cell cycle transitions: $\mathrm{pRb}$ is a critical determinant in blocking DNA replication and in preventing endoreduplication. Mol Cell Biol 1998; 18: 62943.

46 Dulic V, Kaufmann WK, Wilson SJ, TIsty TD, Lees E, Harper JW, et al. p53-dependent inhibition of cyclin-dependent kinase activities in human fibroblasts during radiation-induced $\mathrm{G}_{1}$ arrest. Cell 1994; 76 : 1013-23.

47 Ogryzko VV, Wong P, Howard BH. WAF1 retards S-phase progression primarily by inhibition of cyclin-dependent kinases. Mol Cell Biol 1997; 17: 4877-82.

48 Jung $\mathrm{A}$, Bisaz S, Fleisch $\mathrm{H}$. The binding of pyrophosphate and two diphosphonates by hydroxyapatite crystals. Calcif Tissue Res 1973; 11: $269-80$.

49 Tong HJ, Liu HQ, Wang YY, Yang F, Shi Q, Fernandes JC, et al. A novel in vitro system for intracellular delivery of nonviral DNA. J Orthop Transl 2014; 2: 157-64.

50 Swami A, Reagan MR, Basto P, Mishima Y, Kamaly N, Glavey S, et al. Engineered nanomedicine for myeloma and bone microenvironment targeting. Proc Natl Acad Sci U S A 2014; 111: 10287-92. 